\title{
Heritability of Plant Architecture in Diploid Roses (Rosa spp.)
}

Xuan Wu, Shuyin Liang, and David H. Byrne ${ }^{1}$

Department of Horticultural Sciences, Texas A\&M University, College

Station, Texas 77843-2133

Additional index words. inheritance, genotype-by-environment interaction, growth habit, plant height, node number, primary shoots

\begin{abstract}
Plant architecture is a crucial trait in plant breeding because it is linked to crop yield. For ornamental crops such as roses, plant architecture is key for their aesthetic and economic value. In 2015, six rose plant architectural traits were evaluated on 2- to 3-yearold plants of $F_{1}$ rose populations in May and December in College Station, TX, to estimate variability and heritability. The traits included plant height, the number of primary shoots, the length of primary shoots, the number of nodes on the primary shoot, the number of secondary shoots per primary shoot, and the number of tertiary shoots per primary shoot. Among these traits, plant height, the number of primary shoots, and the length of primary shoots showed a substantial amount of variability, whereas the number of secondary and tertiary shoots per primary shoot were skewed toward zero. Using a random effects model restricted maximum likelihood (REML) analysis, the architectural traits demonstrated low to moderate narrow-sense heritability $(0.12-0.50)$ and low to high broad-sense heritability (0.34-0.92). Plant height and the number of primary shoots changed little after the first growth phase, whereas the other four traits were affected greatly by the genotype-by-environment (growth phase) interaction.
\end{abstract}

Roses, which are admired for their diversity of floral and vegetative characteristics, are members of Rosaceae, the most important horticultural family in the world. They are the world's most important ornamental crop, with an estimated annual production of 18 billion cut stems, 60 to 80 million potted roses, and 220 million roses for landscape uses (Blom and Tsujita, 2003; Pemberton et al., 2003; Roberts et al., 2003). In the United States, 36.6 million garden rose bushes are produced, generating sales of \$203.5 million (U.S. Department of Agriculture, National Agricultural Statistics Service, 2015)

There are four subgenera under the genus Rosa, which has more than 100 species, ranging from diploid to decaploid. There are more than 30,000 cultivars (mainly diploid, triploid, and tetraploid), with a wide interspecific and intraspecific cross-compatibility (Blechert and Debener, 2005; Byrne and Crane, 2003; Cairns, 2000; Jian et al., 2010; Ueckert et al., 2015; Zlesak, 2009). The role roses play in landscapes is extensive, with their use adorning roadsides, public parks, commercial properties, and residential areas. Garden roses provide aesthetic value throughout the growing cycle for both their vegetative and reproductive organs (De Vries and Dubois, 1996).

For ornamental crops like roses, plant architecture is the key factor determining the appearance of the plant and its commercial value. In recent years, researchers have constructed models that describe the plant architecture of rose bushes according to

Received for publication 21 Aug. 2018. Accepted for publication 17 Dec. 2018.

${ }^{1}$ Corresponding author. E-mail: dbyrne@tamu.edu. growth and branching processes. These traits can be characterized morphologically by their number, length, and diameter; by the way they are connected; and by their positioning in space (i.e., shoot angles).

Roses have a wide diversity of plant architectures, ranging from prostrate to compact, highly branched forms to large, spreading to erect bushes to those that climb. Among garden roses, many of these growth forms are useful for specific garden situations, whereas for cutflower roses, a growth form that produces long stems ( $50 \mathrm{~cm}$ or greater), good basal breaking, and little side shoot formation is required.

The Texas A\&M University Rose Breeding and Genetics program has the objective of developing well-adapted (resistant to black spot, Cercospora, and rose rosette disease; tolerant to extreme summer heat), compact, highly floriferous bushes suitable for garden use. Thus, the program is very interested in how a rosebush grows and produces flowers not just during its first flush and growth phase during the spring and early-summer months, but also during the second growth phase in mid- to late-summer and fall months.

The broad-sense heritability of rose architectural traits has been estimated using a set of eight diploid rose cultivars grown in pots in a greenhouse (Crespel et al., 2013, 2014), a small (98 individuals) $F_{1}$ diploid population planted in the field (Kawamura et al., 2011, 2015), and a biparental $F_{1}$ tetraploid cut flower population that was planted under greenhouse conditions in the Netherlands and Kenya (Gitonga et al., 2014). In general, researchers found that the architectural traits they measured during the first flush of growth after dormancy (gardenrose situation) or pruning (cut-rose situation) showed a moderate to high broad-sense herita- bility. Important genotype-by-environment and genotype-by-year interactions were also identified and attributed to differences in total radiation and temperatures that affected total growth rate and budbreak along the stem (Crespel et al., 2014; Gitonga et al., 2014). Kawamura et al. (2011) identified various quantitative trait loci (QTLs) associated with the flower inflorescence structure and identified candidate genes involved in auxin and gibberellin metabolism that controlled node production, internode elongation, and axillary bud branching. Unfortunately, none of these studies analyzed the second growth phase of a garden rose that occurs after the first flush. In Texas, this second growth phase begins in mid to late summer and continues until fall temperatures put the plant into dormancy.

A garden rose needs to flower well not only during this first flush after dormancy, but also throughout the summer and fall months. As the Texas A\&M Rose Breeding and Genetics program has the objective of developing roses that bloom continuously throughout the growing cycle and that establish a compact growth form, our experiment was designed to compare the growth of a set of breeding populations at first flush and later at the end of the year to understand the architectural components important in flower productivity and bush shape. The objective of this research was to evaluate the genetic variation and heritability of six plant architectural components within 13 diploid rose populations.

\section{Materials and Methods}

Plant materials. Thirteen diploid rose populations (Table 1) developed from the hybridization of rose parents with diverse plant architecture including groundcovers derived from crosses with Rosa wichuriana 'Basye's Thornless', the old China roses 'Old Blush' and 'Ducher', and various miniature rose cultivars were used for this study. These populations represent a multispecies breeding background typical in rose breeding. In this case, the species involved are primarily Rosa wichuriana and Rosa chinensis, which are from the related and generally interfertile subgenera Systylae and Chinesis. We evaluated up to 40 seedlings per family; for those less than 40, we evaluated all seedlings.

Field experiment and trait assessment. The seedlings of 13 diploid populations (partial diallel) in this study were planted at a $1 \times 1 \times 3.5-\mathrm{m}$ spacing in a field $2.5 \mathrm{~km}$ from Texas A\&M University in College Station (lat. $30.65 \mathrm{~N}$, long. $-96.32 \mathrm{~W}$ ). Rose plants were planted in rows oriented east to west in an open field. Raised beds were constructed in the field and black cloth weed barrier was placed around the rosebushes for weed control. Irrigation was applied as needed. No pesticides were applied during the evaluation. In March, the rose plants were pruned to a standard size by removing $50 \%$ to $75 \%$ of the previous year's growth. Dead growth was also removed. Each genotype was represented by one plant in the field, and the seedlings from each family were grouped together. Evaluation of the mature (2-3 years 
old) roses for plant architecture was done in the field twice in 2015: spring (May) after the first flower flush; and winter (December), at the end of the growing cycle. Six architectural traits were chosen to represent distinct aspects of variables describing plant architecture to explain the architectural variability observed and to combine correlated variables into one (Crespel et al., 2013). They were plant height (measured in centimeters), the number of primary shoots (initial complete shoots that develop from the base of the plant), the length of the primary shoot (measured in centimeters), the number of nodes on the primary shoot, the number of secondary shoots per primary shoot, and the number of tertiary shoots per primary shoot. Measurements were made on three basal shoots per rose seedling.

Statistical analysis. The statistical analysis used JMP software, version 12. Six architectural traits in 13 diploid rose populations were subjected to normality analysis (original and transformed by taking natural logarithm, base 10 logarithm, and square root) using the Shapiro-Wilk W test. Analysis of variance (ANOVA) was conducted to compare family, growth phase means, and familyby-growth phase interaction. Correlation analysis was conducted among the six traits.

The variance components were calculated with the REML method, assuming all factors as random effects for a more powerful estimation (Littell et al., 1996). The model for heritability analysis was $\mathrm{Y}=\mu+$ Female + Male + Progeny (female, male) + Growth Phase + Growth phase $\times$ Female + Growth phase $\times$ Male + Growth phase $\times$ Progeny (female, male). Because we only have one rose seedling per genotype, residual variance was confounded with Growth phase $\times$ Progeny (female, male) variance. The variances of the parents were considered as additive variance $\left(\mathrm{V}_{\mathrm{A}}\right)$, the progeny variance was considered as nonadditive variance $\left(\mathrm{V}_{\mathrm{D}}\right)$, repeated measurement between May and December data variance was considered as variance of the environment $\left(\mathrm{V}_{\mathrm{E}}\right)$, and the sum of growth phase interactions $\left(\mathrm{V}_{\mathrm{G} \times \mathrm{E}}\right)$ was also estimated, where $\mathrm{G}$ is genotype and $\mathrm{E}$ is environment. Narrow$\left(\mathrm{h}^{2}\right)$ and broad-sense $\left(\mathrm{H}^{2}\right)$ heritability was estimated by the genetic variance from the REML model, where $\mathrm{V}_{\mathrm{P}}=\left(\mathrm{V}_{\mathrm{A}}+\mathrm{V}_{\mathrm{D}}+\right.$ $\mathrm{V}_{\mathrm{G} \times \mathrm{E}} / \mathrm{e}$ ), where $\mathrm{e}$ is the number of environments (first, second growth phase), $h^{2}=V_{A} / V_{P}$, and $\mathrm{H}^{2}=\left(\mathrm{V}_{\mathrm{A}}+\mathrm{V}_{\mathrm{D}}\right) / \mathrm{V}_{\mathrm{P}}$ (Connor et al., 2005; Hallauer et al., 2010; Holland et al., 2003).

To quantify the variation resulting from the genotype-by-environment interaction relative to main genotypic variation, the architectural traits over growth phases were analyzed with a ratio of genotype-by-environmental variance to

Table 1. Thirteen diploid rose families evaluated for six architectural traits in May and December in the field in 2015 at College Station, TX.

\begin{tabular}{llc}
\hline Female parent & Male parent & No. of seedlings evaluated in May, December \\
\hline J06-20-14-3 & Sweet Chariot & 40,40 \\
Sweet Chariot & J06-20-14-3 & 25,25 \\
J06-20-14-3 & Little Chief & 40,36 \\
J06-20-14-3 & Red Fairy & 40,39 \\
J06-20-14-3 & Vineyard Song & 40,37 \\
Vineyard Song & J06-20-14-3 & 11,11 \\
M4-4 & Sweet Chariot & 27,23 \\
Sweet Chariot & M4-4 & 40,39 \\
M4-4 & Vineyard Song & 5,5 \\
Old Blush & J06-30-3-6 & 40,36 \\
Old Blush & M4-4 & 16,15 \\
Old Blush & Red Fairy & 40,40 \\
J06-30-3-3 & Red Fairy & 29,29 \\
\hline
\end{tabular}

genetic variance (Gitonga et al., 2014). Three traits that have a relatively high $\mathrm{V}_{\mathrm{G} \times \mathrm{E}}$ $/ \mathrm{V}_{\mathrm{G}}$ (the number of nodes on the primary shoot, the number of secondary shoots per primary shoot, and the number of tertiary shoots per primary shoot) were subjected to two-way ANOVA to compare means of each trait measured in May and Dec. 2015 of 13 rose families.

\section{Results}

Distribution of six architectural traits. All statistical analyses were based on the original data because the data were either normally distributed (plant height and the length of the primary shoot), or data transformation (log, $\log 10$, and square root) did not improve data normality.

A substantial amount of variability was associated with plant height (range, 14-64 $\mathrm{cm}$ ), the number of primary shoots (range, 353 ), the length of the primary shoot (range, 14-64 cm), and the number of nodes on the primary shoot (range, 3-18). The number of secondary shoots per primary shoot (range, $0-10$ ) and the number of tertiary shoots per primary shoot (range, 0-15) were skewed toward zero (Table 2). The traits that exhibited substantial variability should allow for genetic improvement.

There were differences among the families in all the architectural traits measured as well as differences among the data taken in May vs. December in the number of nodes on the primary shoot, the number of secondary shoots per primary shoot, and the number of tertiary shoots per primary shoot. Although plant height, the number of primary shoots, and the length of the primary shoot were predictable with first growth phase information, the growth of the number of nodes for primary/secondary/tertiary shoots varied among the populations during the growth phases (Tables 2 and 3). Most families, as expected, showed an increased number of secondary/tertiary shoots per primary shoot

Table 2. Mean separations, comparison of growth phases, and genotype-by-environment interaction of six architectural traits for 13 diploid rose families evaluated in the field in May and Dec. 2015 in College Station, TX.

\begin{tabular}{|c|c|c|c|c|c|c|}
\hline Family & Plant ht $(\mathrm{cm})$ & $\begin{array}{l}\text { Primary } \\
\text { shoots }\end{array}$ & $\begin{array}{l}\text { Length of primary } \\
\text { shoots }(\mathrm{cm})\end{array}$ & $\begin{array}{c}\text { No. of nodes } \\
\text { on primary shoot }\end{array}$ & $\begin{array}{l}\text { Secondary shoots/ } \\
\text { primary shoot }\end{array}$ & $\begin{array}{c}\text { Tertiary shoots/ } \\
\text { primary shoot }\end{array}$ \\
\hline J06-20-14-3 × Little Chief & $27 \mathrm{f}$ & $18 \mathrm{e}$ & $32 \mathrm{fg}$ & $12.0 \mathrm{ab}$ & $4.3 \mathrm{ab}$ & $4.1 \mathrm{a}$ \\
\hline J06-20-14-3 × Red Fairy & $37 \mathrm{~d}$ & $22 \mathrm{~d}$ & $42 \mathrm{bc}$ & $10.9 \mathrm{bc}$ & $3.9 \mathrm{bc}$ & $3.0 \mathrm{bc}$ \\
\hline J06-20-14-3 × Sweet Chariot & $39 \mathrm{~cd}$ & $27 \mathrm{ab}$ & 35 ef & $9.1 \mathrm{e}$ & $3.0 \mathrm{df}$ & $1.7 \mathrm{de}$ \\
\hline J06-20-14-3 $\times$ Vineyard Song & $38 \mathrm{~cd}$ & $24 \mathrm{bd}$ & $43 \mathrm{bc}$ & $11.4 \mathrm{bc}$ & 2.7 ef & $1.0 \mathrm{e}$ \\
\hline J06-30-3-3 × Red Fairy & $39 \mathrm{bd}$ & $21 \mathrm{de}$ & $39 \mathrm{~cd}$ & $9.6 \mathrm{de}$ & $3.9 \mathrm{bc}$ & $3.5 \mathrm{ac}$ \\
\hline M4-4 × Sweet Chariot & $32 \mathrm{e}$ & $23 \mathrm{bd}$ & $36 \mathrm{df}$ & $9.4 \mathrm{de}$ & $3.3 \mathrm{ce}$ & $2.2 \mathrm{ce}$ \\
\hline M4-4 × Vineyard Song & 38 be & $31 \mathrm{ac}$ & $54 \mathrm{a}$ & $14.1 \mathrm{a}$ & $5.8 \mathrm{a}$ & $3.7 \mathrm{ae}$ \\
\hline Old Blush $\times$ J06-30-3-3 & 39 bd & $23 \mathrm{bd}$ & 39 ce & $8.4 \mathrm{ef}$ & $2.4 \mathrm{f}$ & $1.6 \mathrm{de}$ \\
\hline Old Blush $\times$ M4-4 & $36 \mathrm{de}$ & $25 \mathrm{bd}$ & $29 \mathrm{~g}$ & $6.7 \mathrm{f}$ & $2.7 \mathrm{df}$ & $3.1 \mathrm{ad}$ \\
\hline Old Blush $\times$ Red Fairy & $45 \mathrm{a}$ & $13 \mathrm{f}$ & $39 \mathrm{~cd}$ & $9.2 \mathrm{e}$ & $2.9 \mathrm{ef}$ & $1.6 \mathrm{de}$ \\
\hline Sweet Chariot $\times$ J06-20-14-3 & $37 \mathrm{~d}$ & $23 \mathrm{~cd}$ & $43 \mathrm{bc}$ & $12.9 \mathrm{a}$ & $4.4 \mathrm{ab}$ & $3.8 \mathrm{ab}$ \\
\hline Sweet Chariot $\times$ M4-4 & $41 \mathrm{bc}$ & $26 \mathrm{bc}$ & $39 \mathrm{~cd}$ & $10.5 \mathrm{~cd}$ & $3.8 \mathrm{bd}$ & $3.2 \mathrm{ac}$ \\
\hline Vineyard Song $\times$ J06-20-14-3 & $45 \mathrm{ab}$ & $33 \mathrm{a}$ & $48 \mathrm{ab}$ & $12.6 \mathrm{ac}$ & $2.5 \mathrm{cf}$ & $1.1 \mathrm{ce}$ \\
\hline Significance & $* * *$ & $* * *$ & $* * *$ & $* * *$ & $* * *$ & $* * *$ \\
\hline May $^{z}$ & $39(17-62)$ & $23(3-53)$ & $39(17-64)$ & $9.5(3-17)$ & $2.0(0-6)$ & $0.7(0-6)$ \\
\hline December & $38(14-64)$ & $23(3-51)$ & $37(14-62)$ & $10.4(4-18)$ & $4.5(0-10)$ & $4.2(0-15)$ \\
\hline Significance & NS & NS & NS & $* * *$ & $* * *$ & $* * *$ \\
\hline Genotype $\times$ growth phase & NS & NS & $*$ & $* * *$ & $* * *$ & $* * *$ \\
\hline
\end{tabular}

NS, $* * *, * * *$ Nonsignificant or significant at $P \leq 0.05,0.01$, or 0.001 , respectively.

Levels not connected by same letter are significantly different and the mean separation is within a column.

${ }^{\mathrm{z}}$ Mean (range). 
(11 of 13 and 12 of 13 , respectively) in December compared with May (Table 4).

Correlation analysis. Among the six architectural components, plant height and the number of primary shoots exhibited low correlation $(R=0.39)$. Components that were moderately correlated include plant height and the length of the primary shoot $(R=0.52)$, the length of the primary shoot and the number of nodes on the primary shoot $(R=0.59)$, the number of nodes on the primary shoot and the number of the secondary shoots per primary shoot $(R=0.48)$, and the number of secondary shoots per primary shoot and the number of tertiary shoots per primary shoot $(R=0.62) . R^{2}$ values indicate these correlations could explain between $20 \%$ to $40 \%$ of the variation, and therefore, are not high enough to use for selection purposes.

Heritability analysis. The six architectural traits measured exhibited low to high broadsense heritability (0.34-0.92) and low to moderate narrow-sense heritability $(0.12-0.50)$ (Table 5), which indicated that architectural traits are feasible targets of rose breeding.

Plant height was found highly heritable with a moderate narrow-sense heritability $\left(\mathrm{h}^{2}=0.50\right)$ and high broad-sense heritability $\left(\mathrm{H}^{2}=0.82\right)$ (Table 5). This finding was consistent with estimates reported previously by Gitonga et al. (2014) $\left(\mathrm{H}^{2}=0.82\right)$, who measured this architectural component on potted tetraploid cut-flower rose populations, and by Kawamura et al. (2015) $\left(\mathrm{H}^{2}=0.88\right)$, who studied the architecture of a small (98 individuals) diploid garden-rose population. Both studies reported broad-sense heritability only and have smaller populations and fewer families than our study.

The number of primary shoots had a low narrow-sense heritability $\left(\mathrm{h}^{2}=0.27\right)$ and high broad-sense heritability $\left(\mathrm{H}^{2}=0.92\right)$, indicating a strong nonadditive genetic component. This accounted for $\approx 60 \%$ of total phenotypic variance and was more than twice that of the narrow-sense estimate for this trait (Table 5). Previous studies evaluated the number of long axes (shoots with five or more metamers each which consist of an internode, a node, an axillary bud and a leaf) and the number of determined axes (axes ended in a flower bud or a flower) (Crespel et al., 2013, 2014)—which are equivalent to some extent to the number of primary shoots in our study. The broad-sense heritability for the number of long axes and the number of determined axes assessed using eight diploid garden-rose cultivars in the greenhouse by Crespel et al. (2014) were 0.70 and 0.64 , respectively, and thus were less than the number of primary shoots $\left(\mathrm{H}^{2}=0.92\right)$ (Table 5) in our study using segregating populations of diploid garden roses.

The length of the primary shoot showed low narrow-sense $\left(\mathrm{h}^{2}=0.20\right)$ and a moderately high broad-sense $\left(\mathrm{H}^{2}=0.64\right)$ heritability (Table 5$)$. This is greater than a previous report by Crespel et al. (2014) on the length of the long axes $\left(\mathrm{H}^{2}=\right.$ $0.48)$. Nonadditive genetic variance compo- nents accounted for $\approx 32 \%$ of phenotypic variance compared with $15 \%$ (Table 5) for the additive genetic component.

The number of nodes on the primary shoot revealed low narrow-sense $\left(\mathrm{h}^{2}=0.12\right)$ and moderate broad-sense $\left(\mathrm{H}^{2}=0.46\right)$ heritability (Table 5). Crespel et al. (2014) reported that the broad-sense heritability of the number of metamers (an internode, a node, an axillary bud, and a leaf) of the long axes (equivalent to the number of nodes on primary shoots) was 0.95 , which is double that found in our study $\left(\mathrm{H}^{2}=0.46\right)$ (Table 5). This is probably, in part, a result of the inclusion of extreme growth types in their study that would inflate the total variation compared with the segregating population in our study.

The number of secondary and tertiary shoots per primary shoot had low narrowsense $\left(\mathrm{h}^{2}=0.16\right.$ and 0.21 , respectively) and low to moderate broad-sense heritability $\left(\mathrm{H}^{2}=0.34\right.$ and 0.48 , respectively) (Table 5).

Genotype-by-environment interaction. Ornamental plants are expected to be attractive throughout the year. With a rosebush, this requires that the bush remains well leafed, compact, and continues to flower throughout the annual growing cycle. Thus, in our analysis, the different environments refer to the two phases of rose growth during the growing cycle. First phase is the first flush of a rose plant during which it emerges from dormancy and develops the bush shape and

Table 3. Two-way analysis of variance comparing means of the length of the primary shoot and the number of nodes on the primary shoot for 13 diploid rose families characterized in May and Dec. 2015 in College Station, TX.

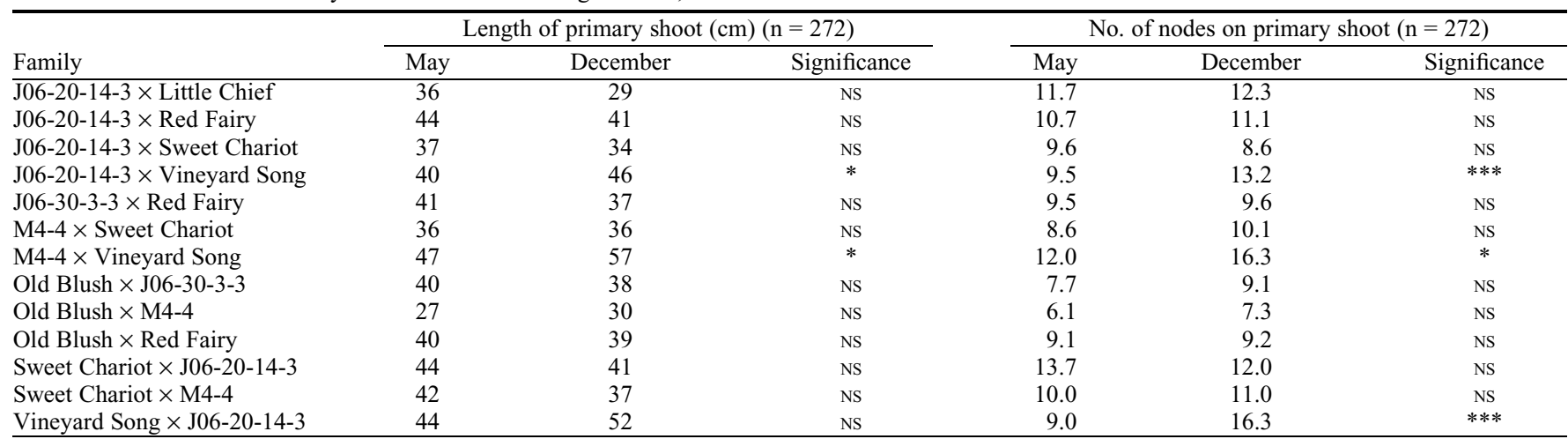

NS, *,**,**Nonsignificant or significant at $P \leq 0.05,0.01$, or 0.001 , respectively.

Table 4. Two-way analysis of variance comparing means of the number of secondary and tertiary shoots per primary shoot for 13 diploid rose families characterized in May and Dec. 2015 in College Station, TX.

\begin{tabular}{|c|c|c|c|c|c|c|}
\hline & \multicolumn{3}{|c|}{ Secondary shoots/primary shoot $(n=272)$} & \multicolumn{3}{|c|}{ Tertiary shoots/primary shoot $(\mathrm{n}=272)$} \\
\hline & May & December & Significance & May & December & Significance \\
\hline J06-20-14-3 × Little Chief & 3.3 & 5.3 & $* * *$ & 2.0 & 6.3 & $* * *$ \\
\hline J06-20-14-3 × Red Fairy & 3.0 & 4.7 & $* * *$ & 1.2 & 4.8 & $* * *$ \\
\hline J06-20-14-3 × Sweet Chariot & 2.2 & 3.8 & $* * *$ & 0.7 & 2.7 & $* *$ \\
\hline J06-20-14-3 $\times$ Vineyard Song & 0.8 & 4.6 & $* * *$ & 0.1 & 1.9 & * \\
\hline J06-30-3-3 × Red Fairy & 2.9 & 4.9 & $* * *$ & 1.4 & 5.7 & $* * *$ \\
\hline M4-4 × Sweet Chariot & 1.9 & 4.7 & $* * *$ & 0.6 & 3.8 & $* * *$ \\
\hline M4-4 × Vineyard Song & 2.0 & 7.7 & $* * *$ & 1.3 & 6.0 & * \\
\hline Old Blush $\times$ J06-30-3-3 & 1.1 & 3.7 & $* * *$ & 0.1 & 3.1 & $* * *$ \\
\hline Old Blush $\times$ M4-4 & 0.7 & 4.8 & $* * *$ & 0.2 & 5.9 & $* * *$ \\
\hline Old Blush $\times$ Red Fairy & 1.7 & 4.0 & $* * *$ & 0.3 & 3.0 & $* * *$ \\
\hline Sweet Chariot $\times$ J06-20-14-3 & 4.4 & 4.4 & NS & 2.3 & 5.3 & $* * *$ \\
\hline Sweet Chariot $\times$ M4-4 & 2.6 & 5.0 & $* * *$ & 1.1 & 5.4 & $* * *$ \\
\hline Vineyard Song $\times$ J06-20-14-3 & 2.0 & 3.0 & NS & 0.5 & 1.8 & NS \\
\hline
\end{tabular}

$\mathrm{NS}, *, * *, * * *$ Nonsignificant or significant at $P \leq 0.05,0.01$, or 0.001 , respectively. 
Table 5. Variance component, broad-sense heritability $\left(\mathrm{H}^{2}\right)$, and narrow-sense heritability $\left(\mathrm{h}^{2}\right)$ for six plant architectural traits evaluated in the field on 13 diploid rose families in May and Dec. 2015 in College Station, TX.

\begin{tabular}{|c|c|c|c|c|c|c|c|c|c|c|}
\hline \multirow[b]{2}{*}{ Traits } & \multirow[b]{2}{*}{$\mathrm{n}$} & \multirow[b]{2}{*}{$R^{2}$} & \multirow[b]{2}{*}{$\mathrm{V}_{\mathrm{A}}$} & \multicolumn{5}{|c|}{ Variances $^{z}$} & \multirow[b]{2}{*}{$h^{2}$} & \multirow[b]{2}{*}{$\mathrm{H}^{2}$} \\
\hline & & & & $\mathrm{V}_{\mathrm{D}}$ & $\mathrm{V}_{\mathrm{G}}$ & $\mathrm{V}_{\mathrm{G} \times \mathrm{E}}$ & $\mathrm{V}_{\mathrm{P}}$ & $\mathrm{V}_{\mathrm{G} \times \mathrm{E}} / \mathrm{V}_{\mathrm{G}}$ & & \\
\hline$\overline{\text { Plant height }(\mathrm{cm})}$ & 750 & 0.70 & 56.4 & 36.9 & 93.3 & 40.1 & 113.4 & 0.43 & 0.50 & 0.82 \\
\hline No. of primary shoots & 750 & 0.90 & 35.8 & 85.2 & 121.0 & 22.1 & 132.1 & 0.18 & 0.27 & 0.92 \\
\hline Length of primary shoot $(\mathrm{cm})$ & 544 & 0.68 & 17.9 & 38.7 & 56.6 & 62.4 & 87.9 & 1.10 & 0.20 & 0.64 \\
\hline No. of nodes on primary shoot & 544 & 0.61 & 1.2 & 3.2 & 4.4 & 10.1 & 9.5 & 2.30 & 0.12 & 0.46 \\
\hline Secondary shoots/primary shoot & 544 & 0.53 & 0.31 & 0.37 & 0.68 & 2.59 & 1.98 & 3.90 & 0.16 & 0.34 \\
\hline Tertiary shoots/primary shoot & 544 & 0.56 & 1.23 & 1.61 & 2.83 & 6.03 & 5.85 & 2.13 & 0.21 & 0.48 \\
\hline
\end{tabular}

the first flush of flowers. In Texas, the second phase of growth starts after the first flush of flowers in early summer and continues until fall temperatures stop growth. Among six architectural traits, plant height and the number of primary shoots showed a weak genotype-byenvironment interaction, as indicated by the low $\mathrm{V}_{\mathrm{G} \times \mathrm{E}}$ to $\mathrm{V}_{\mathrm{G}}$ ratios $(0.43$ and 0.18 , respectively) (Table 5), reflecting consistency across growth phases. The length of the primary shoot was moderately affected by the genotype-byenvironment interaction $\left(\mathrm{V}_{\mathrm{G} \times \mathrm{E}} / \mathrm{V}_{\mathrm{G}}\right.$ ratios of 1.10) (Table 5). These first three traits changed little after the first flush among these remontant rose populations, indicating that these traits have little influence over the flowering behavior of the rose during the second growth phase.

Strong genotype-by-environment interactions were found for the number of nodes on the primary shoot, and the number of secondary shoots and tertiary shoots per primary shoot $\left(\mathrm{V}_{\mathrm{G} \times \mathrm{E}} / \mathrm{V}_{\mathrm{G}}\right.$ ratios of 2.3, 3.9, and 2.1, respectively) (Table 5). Previously, ANOVA (Tables 2-4) indicated that, after the initial growth of the primary shoots in the spring, additional growth continued mainly by the development of secondary and tertiary shoots during the second growth phase of the rosebush. These genotype-by-environment interactions indicate a differential response of genotypes to the environment in which they are grown (Allard and Bradshaw, 1964; Bernardo, 2010). For the length of the primary shoot and the number of nodes on the primary shoot, the genotype-by-environment interaction was mainly the result of the behavior of the families with 'Vineyard Song' as a parent. These grew longer and put on more nodes during the Mayto-December time period than the other families. The number of secondary and tertiary shoots formed during this second growth phase varied among the roses, and thus so did their ability to produce new foliage and flowers - an essential requirement to keep the rosebush attractive throughout the growing cycle.

\section{Discussion}

The six architectural traits measured exhibited low to high broad-sense heritability (0.34-0.92) and low to moderate narrow-sense heritability $(0.12-0.50)$. Broad-sense heritability has been used widely for estimating the accuracy of selection for genetic traits
(Holland et al., 2003) and QTL analysis (Beavis, 1998). Because rose is a vegetatively propagated crop, the nonadditive genetic component of the variation can be captured easily by clonal propagation. The following conclusions can be drawn from this study.

Our results, combined with previous studies (Crespel et al., 2014; Kawamura et al., 2015) that reported high broad-sense heritability for several architectural traits of garden roses, indicated that rose plant architecture was a feasible target for rose breeding. Architectural traits with low narrow-sense heritability but moderately high to high broad-sense heritability, such as the number of primary shoots, the length of the primary shoot, and the number of nodes on the primary shoot, indicated important nonadditive effects.

Architectural traits were affected by the genotype-by-environment interaction to different extents. Plant height and the number of primary shoots were highly heritable and changed little during the second growth phase. These can be selected for reliably and accurately during the first growth phase. The number of secondary and tertiary shoots per primary shoot showed lower heritability and tended to increase in number as the year progressed. The extent of this side shoot growth varied by population (high genotype-byenvironment interaction). This indicated that selection during the first growth phase would not predict the final number of secondary/ tertiary shoots forming throughout the year. Therefore, selection during both growth phases was recommended. Finally, for the selection of roses that flower continuously throughout the year, it is essential to select for high production of basal shoots during the first growth phase and high production of secondary and tertiary shoots during both growth phases.

\section{Literature Cited}

Allard, R.E. and R.W. Bradshaw. 1964. Implications of genotype-environment interactions in applied plants breeding. Crop Sci. 4:503-508.

Beavis, W.D. 1998. QTL analyses: Power, precision, and accuracy, p. 145-162. In A.H. Paterson (ed.). Molecular dissection of complex traits. CRC Press, New York, NY.

Bernardo, R. 2010. Breeding for quantitative traits in plants. 2nd ed. Stemma Press, Woodbury, MN.

Blechert, O. and T. Debener. 2005. Morphological characterization of the interaction between
Diplocarpon rosae and various rose species. Plant Pathol. 54:82-90.

Blom, T.J. and M.J. Tsujita. 2003. Cut rose production, p. 594-600. In: A.V. Roberts, T. Debener, and S. Gudin (eds.). Encyclopedia of rose science. Elsevier, Oxford, UK.

Byrne, D.H. and Y.M. Crane. 2003. Meiosis, p. 273-279. In: A.V. Roberts, T. Debener, and S. Gudin (eds.). Encyclopedia of rose science. Elsevier, Oxford, UK.

Cairns, T. 2000. Modern roses XI: The world encyclopedia of roses. Academic Press, San Diego, CA.

Connor, A.M., M.J. Stephens, H.K. Hall, and P.A. Alspach. 2005. Variation and heritabilities of antioxidant activity and total phenolic content estimated from a red raspberry factorial experiment. J. Amer. Soc. Hort. Sci. 130:403-411.

Crespel, L., C. Le Bras, D. Relion, and P. Morel. 2014. Genotype $\times$ year interaction and broadsense heritability of architectural characteristics in rose bush. Plant Breed. 133(3):412-418.

Crespel, L., M. Sigogne, N. Donès, D. Relion, and P. Morel. 2013. Identification of relevant morphological, topological and geometrical variables to characterize the architecture of rose bushes in relation to plant shape. Euphytica 191(1):129-140.

De Vries, D.P. and L.A.M. Dubois. 1996. Rose breeding: Past, present, prospects. Acta Hort. 424:241-248.

Gitonga, V.W., C.F.S. Koning-Boucoiran, K. Verlinden, O. Dolstra, R.G.F. Visser, C. Maliepaard, and F.A. Krens. 2014. Genetic variation, heritability and genotype by environment interaction of morphological traits in a tetraploid rose population. BMC Genet. 15:1-14.

Hallauer, A.R., M.J. Carena, and J.B. Miranda Filho. 2010. Quantitative genetics in maize breeding. Springer, New York, NY.

Holland, J.B., W.E. Nyquist, and C.T. CervantesMartínez. 2003. Estimating and interpreting heritability for plant breeding: An update. Plant Breed. Rev. 22:9-112.

Jian, H., H. Zhang, K. Tang, S. Li, Q. Wang, T. Zhang, X. Qiu, and H. Yan. 2010. Decaploidy in Rosa praelucens Byhouwer (Rosaceae) endemic to Zhongdian plateau, Yunnan, China. Caryologica 63:162-167.

Kawamura, K., L. Hibrand-Saint Oyant, L. Crespel, T. Thouroude, D. Lalanne, and F. Foucher. 2011. Quantitative trait loci for flowering time and inflorescence architecture in rose. Theor. Appl. Genet. 122:661-675.

Kawamura, K., L. Hibrand-Saint Oyant, T. Thouroude, J. Jeauffre, and F. Foucher. 2015. Inheritance of garden rose architecture and its association with flowering behaviour. Tree Genet. Genomes 11 (2): $1-12$.

Littell, R.C., G.A. Milliken, W.W. Stroup, and R.D. Wolfinger. 1996. SAS system for mixed models. SAS Institute, Inc., Cary, NC.

Pemberton, H.B., J.W. Kelly, and J. Ferare. 2003. Pot rose production, p. 587-593. In: A.V. Roberts, T. Debener, and S. Gudin (eds.). Encyclopedia of rose science. Elsevier, Amsterdam, Netherlands.

Roberts, A.V., T. Debener, and S. Gudin. 2003. Introduction, p. vi-vii. In: A.V. Roberts, T. Debener, and S. Gudin (eds.). Encyclopedia of rose science. Elsevier, Amsterdam, Netherlands.

Ueckert, J., D.H. Byrne, K. Crosby, G. Hodnett, and D. Stelly. 2015. The utilization of the polyploid nature of roses. Acta Hort. 1064:73-78.

U.S. Department of Agriculture, National Agricultural Statistics Service. 2015. Census of horticultural specialties (2014): Specialty studies. Vol. 3, part 3.

Zlesak, D.C. 2009. Pollen diameter and guard cell length as predictors of ploidy in diverse rose cultivars, species, and breeding lines. Fla. Orn. Biotech. 3:53-70. 